\title{
SENTENCIA DEL TRIBUNAL DEL JUICIO ORAL EN LO PENAL DE LA SERENA. ROBO CON INTIMIDACIÓN
}

La Serena, veintiséis de marzo del año dos mil uno.

\section{VISTOS:}

PRIMERQ: Que, con fecha veintiuno de marzo de dos mil uno, ante esta Primera Sala del Tribunal de Juicio Oral en lo Penal de la ciudad de La Serena, constituida por el Juez Presidente de Sala señor Jaime Meza Sáez y los Jueces señores Jorge Fernández Stevenson y Enrique Durán Branchi, se llevó a efecto la audiencia del Juicio Oral relativa a los autos rol $N^{\circ} 1-2001$, seguidos contra CRISTIAN ANDRES SENZANO GODOY, chileno, casado, 21 años de edad, cédula de identidad $N^{\circ}$ 10.780.905-8, domiciliado en calle Mar Jónico N¹77, Villa Portugal, San Juan de Coquimbo, condenado anteriormente por los siguientes tribunales: a) Segundo Juzgado del Crimen de Coquimbo, como autor del delito de robo en lugar no habitado, causa rol $N^{\circ} 24.076-99$, pena remitida y b) Tercer Juzgado de Letras de Coquimbo, como autor de los delitos de hurto y hurto falta, causa rol N452-99, en la que se concedió el beneficio de la reclusión nocturna.

Fue parte acusadora en el presente juicio el Ministerio Público, con domicilio en calle Doctor Marín N³02 de la ciudad de Coquimbo, representado por don Rodrigo de la Barra Cousiño.

La defensa del encausado estuvo a cargo de los abogados Diego Falcone Salas e Inés Lorena Rojas Varas, de la Defensoría Penal Pública de Coquimbo.

SEGUNDO: Que, los hechos materia de la acusación, según el auto de apertura del juicio oral, tuvieron lugar el 19 de diciembre del año 2000, cerca de las 19:00 horas, en las personas y en perjuicio de Luis Araya Barraza y Ana Luz Cisternas Rojas, en su domicilio de calle Los Copihues N¹336, Villa Portugal, San Juan, Coquimbo, en circunstancias que el referido imputado habría ingresado al domicilio de los afectados y mediante intimidación con arma cortopunzante, sustrajo diversas especies de propiedad de las mencionadas víctimas.

Contestando la acusación deducida en su contra, la defensa del imputado expuso que los hechos de la causa no tienen la calificación de robo con intimidación. Manifiesta que el acusado estaba bebido y salió a la calle con unos amigos, donde tiró piedras a una capilla y obstaculizó el paso de un microbús, dándose cuenta que lo observaba el señor Araya desde su amasandería y con el objeto que no lo denunciara, tomó un machete y lo fue a amenazar de muerte, lo que hizo; como asimismo rompió 
una máquina heladera sin sustraer nada de ella. Agrega que robo no hubo, sino sólo amenazas.

TERCERO: Que, son hechos no controvertidos en la causa, por haber sido materia de convención probatoria, los siguientes: a) el de encontrarse bebido el imputado, el día y hora de la ocurrencia de los hechos; b) que el imputado arrojaba piedras en la vía pública, fuera del local de la amasandería, ubicado en el domicilio de las víctimas, el día y hora de los hechos; c) el de encontrarse el imputado acompañado por otras personas el día, hora y en el lugar de ocurrencia de los hechos, y d) el de haber ingresado el imputado al local de amasandería ubicado en el domicilio de las víctimas, el día y hora de ocurrencia de los hechos.

CUARTO: Que, en consecuencia, de conformidad al objeto del juicio, corresponde establecer la existencia de los siguientes hechos que puedan ser atribuidos al imputado: a) la sustracción de cosa mueble ajena con ánimo de lucro, de propiedad de los ofendidos, y b) intimidación en su contra consistente en amenaza, ya para hacer que se entreguen o manifiesten las cosas, ya para impedir la resistencia u oposición a que se quiten o cualquier otro acto que pueda intimidar o forzar la manifestación o entrega.

QUINTO: Que, en lo relativo a la sustracción de cosa mueble ajena con ánimo de lucro, elemento del tipo penal objeto de la acusación, ésta no ha sido probada en autos, toda vez que:

1.- El ofendido don Luis Araya Barraza en su contrainterrogación dijo que no vio quien sacó las bebidas y, que ni el agresor ni sus acompañantes le pidieron dinero u otras especies.

2.- La ofendida doña Ana Luz Cisternas Rojas tampoco vio sustracción de especies por parte del imputado.

3.- Es, además, insuficiente para estos efectos la declaración del sargento de Carabineros Carlos Videla Trujillo, quien concurrió ante el llamado radial al lugar de los hechos, el que expone sólo que las botellas estaban fuera del local comercial, junto a la muralla que queda al lado de la puerta de acceso de éste, dentro del ante jardín del inmueble. Contrainterrogado expone que tampoco vio quien sacó las bebidas de la máquina.

4.- Del mismo modo, es también insuficiente e irrelevante para probar la sustracción el hecho que las bebidas aún estuviesen húmedas al momento de ser devueltas por carabineros, según lo expuso el afectado Luis Araya Barraza. 
5.- Finalmente, los dichos de Ana Luz Cisternas Rojas, tampoco resultan idóneos para estos efectos, en cuanto señala que uno de los acompañantes del agresor tomó un frasco con dulces, pues por una parte éstos fueron devueltos inmediatamente en forma voluntaria por la misma persona, y por otra, se ignora la existencia de comunicabilidad de aquél con el imputado.

SEXTO: Que, en lo relativo a la intimidación, ésta no ha resultado acreditada en el juicio, ya que no existe ningún elemento de prueba que permita vincular las amenazas proferidas por el imputado con sustracción alguna o intención en tal sentido, según lo expuesto en el considerando precedente. En la especie existe amenaza, pero no aquella propia de uno de los elementos del tipo en el delito de robo con intimidación.

Lo anterior tiene como base de razonamiento la declaración del afectado Luis Araya Barraza, quien expresa que luego de haber visto al imputado realizado desmanes en la calle, momentos después observó a cuatro personas, dos de las cuales entraron al local, siendo uno de éstos el acusado. Este portaba un sable o machete, y trepó al mostrador diciéndole "sapo, concha de tu madre, te voy a matar". Agrega que trató de tranquilizarlo, ya que se sentía en peligro; en seguida, al llegar su cónyuge, ésta se puso en medio para que no continuara el hecho.

Lo expuesto en el párrafo anterior está conteste con lo declarado por la afectada Ana Luz Cisternas Rojas, quien expresa que en el día y hora de los hechos se encontraba en el segundo piso del inmueble y al sentir gritos y amenazas desde el negocio, bajó y vio al imputado con un machete amenazando de muerte a su marido, versión que se complementa con la declaración de la testigo de la defensa Lidia González Salazar, quien manifestó que el día y hora de los hechos fue a comprar al negocio de los afectados y vio en la calle a Cristian Senzano llevando un cuchillo en la mano, quien entró al local profiriendo insultos, oyendo decir "viejo culiao, concha de tu madre" y gritar a la señora de Araya Barraza.

Finalmente, todas las declaraciones anteriores se encuentran reafirmadas con la confesión del acusado Cristian Andrés Senzano Godoy quien expresó que como había tirado una piedra a una Iglesia y lo observó el señor Araya, tenía miedo que lo denunciara por ello, ya que no quería volver a la cárcel. Debido a esto, fue a su casa a buscar un machete, concurrió al negocio del ofendido y lo amenazó de muerte, diciéndole además "sapo, concha de tu madre".

De este modo, con las pruebas anteriormente indicadas, apreciadas libremente, conforme lo dispone el artículo 297 del Código Procesal Penal, se tiene por acreditado que un sujeto, el 19 de diciembre de 2000, alrededor de las 19:00 horas, entró al negocio del afectado Luis Araya Barraza empuñando un machete en sus manos, y desde atrás de un mostrador, lo amenazó de muerte. 
SEPTIMO: Que, el hecho referido en el fundamento precedente configura sólo el delito de amenazas no condicional, previsto y sancionado en el artículo $296 \mathrm{~N}^{\circ} 3$ del Código Penal, toda vez que el día y hora de los hechos de la acusación, una persona amenazó de muerte a Luis Roberto Araya Barraza, amenazas que se encuentran revestidas de seriedad y credibilidad atendidas las características del arma cortopunzante que portaba y la conducta agresiva del imputado, lo que produjo un evidente y fundado temor en las víctimas.

Está así probado que existieron graves, serias y verosímiles amenazas contra el ofendido Luis Araya Barraza dentro de su local comercial, por parte del imputado, consistentes explícitamente en amenazas de muerte, mientras blandía el arma blanca hechiza acompañada en el juicio, como se reseña en el considerando sexto de este fallo.

Esta conducta es igualmente susceptible de reproche desde el punto de vista penal, no obstante el agente no tenga pretensión alguna en orden a exigir, condicionar o imponer acciones singulares o determinadas al ofendido. La rudeza de la agresión verbal de que hizo gala el imputado era verosímil y eficazmente respaldada con la contundente arma blanca hechiza referida y que portaba entre sus manos, razón por la que su ocurrencia se hacía seriamente previsible por el imputado.

OCTAVO: Que, si bien es cierto que conforme el artículo 54 del Código Procesal Penal la amenaza constituye un delito de acción pública previa instancia particular, lo que implica jurídicamente que en aquellos no puede procederse de oficio sin que, a lo menos, el ofendido hubiere denunciado el hecho a la justicia, al ministerio público o a la policía, se estima que en la especie se dio cabal cumplimiento a las referidas exigencias legales, toda vez que existió denuncia por parte de los ofendidos al personal policial que llegó al lugar de los hechos acerca del atentado de que habían sido objeto momentos antes, y es el Tribunal el que está facultado para calificar jurídicamente los mismos, tal como lo ha hecho en autos. Por otra parte, y de cualquier modo, el tribunal también estima que en la especie cabe aún dar aplicación al inciso $4^{\circ}$ del artículo 54 Código Procesal Penal, entendiendo que la dinámica de los hechos no permitía a los ofendidos actuar de otro modo como lo hicieron, evento en que el ministerio público se encuentra facultado para actuar de oficio.

NOVENO: Que, respecto del delito de amenaza no condicional que se ha dado por acreditado en autos, el acusado ha tenido participación inmediata y directa, esto es, en calidad de autor, lo cual resulta de los siguientes elementos de prueba: a) declaración de los afectados Luis Araya Barraza y Ana Luz Cisternas Rojas, quienes vieron al imputado con un machete en la mano amenazando de muerte al primero; b) testimonio de Lidia González Salazar, quien vio al imputado ingresar al local de los ofendido portando un cuchillo en sus manos y profiriendo insultos; y c) confesión de 
Cristian Andrés Senzano Godoy, quien expuso en el juicio haber tenido el machete en la mano y haber amenazado de muerte a la citada persona dentro de su negocio.

DECIMO: Que, atendido lo expuesto precedentemente, se ha acogido la posición de la defensa en cuanto sancionar al acusado por el ilícito de amenaza no condicional.

Consecuencialmente, se rechaza la calificación jurídica de los hechos objeto de la acusación efectuada por el Ministerio Público.

UNDECIMO: Que, la declaración de los carabineros Luis Adrián Bustamante Roa, Carlos Toledo Espinoza, Jorge Caneo Fernández, Miguel Ángel Berríos González, la abogada de la fiscalía Catalina Duque, el testigo Daniel López Gómez y la madre del acusado Susana Godoy Godoy, quienes depusieron en el juicio acerca de la cadena de la prueba material consistente en el arma blanca, dos botellas de bebidas y un frasco de plástico con dulces en su interior, más una bolsa conteniendo vidrios, constituye una situación que no fue controvertida en el juicio según los alegatos de las partes y declaración del imputado.

Por su parte, la declaración del padrastro del imputado, Marco Tabilo Vergara, quien expresa que trabaja en la embotelladora Coca Cola Polar S.A. desde el primero de junio de 1993, lo que acredita la defensa, además, con la presentación de su contrato de trabajo, tampoco tiene incidencia en los hechos que se han dado por acreditados en el juicio.

En cuanto a las fotografías, a los trozos de vidrio y plástico, como asimismo del arma cortopunzante presentadas en el juicio por el Ministerio Público, éstas pruebas no han sido controvertidas por las partes.

En lo relativo a las especies supuestamente sustraídas, el tribunal ya se hizo cargo de esta circunstancia en el considerando quinto.

DUODECIMO: Que el Tribunal desestimará la agravante del artículo $12 \mathrm{~N}^{\circ} 14$ alegada por el Ministerio Público, esto es, haber cometido el imputado el delito por el que ahora se le juzga después de haber quebrantado una condena anterior, toda vez que esta última le fue suspendida al beneficiársele con la medida alternativa de la remisión condicional de la pena, conforme lo indica el artículo 3 de la ley 18.216, y por tanto, no ha habido en la especie cumplimiento efectivo de aquella condena ni pudo, consecuencialmente, existir quebrantamiento de la misma.

De otra parte, y aún cuando se diere la hípótesis legal a que la señalada agravante se refiere -y conforme lo indica la doctrina- aquella tampoco resulta aplicable conforme lo dispuesto en el artículo 63 del Código Penal, toda vez que en tal caso, el 
quebrantamiento de condena constituye en sí mismo un delito, sancionado con una pena específica, y no surte efecto como agravante.

En estos términos, la situación referida constituye una infracción diversa, señalada en el artículo 26 de la ley antedicha, como se decide en lo resolutivo de este fallo.

DECIMO TERCERO: Que, tampoco se acogerá la agravante solicitada del artículo 456 bis $\mathrm{N}^{\circ} 5$ del Código Penal, esto es, actuar con personas exentas de responsabilidad penal, según el número $1^{\circ}$ del artículo 10 del mismo cuerpo legal, situación que no se da en la especie, no habiéndose acreditado haber actuado el imputado con personas afectadas por locura o demencia o que por causas independientes de su voluntad, se hallen privados totalmente de razón, que son las situaciones a que tal norma se refiere.

DECIMO CUARTO: Que, no existiendo circunstancias modificatorias de responsabilidad penal que ponderar, y pudiendo recorrer el Tribunal en toda su extensión la pena asignada al ilícito para su determinación, se fijará en el monto que se indica en la parte resolutiva, considerando, además, para ello, el daño psicológico que los hechos produjeron a la víctima Ana Luz Cisternas Rojas, según los dichos del testigo Claudio de la Fuente presentado por su parte.

Por estas consideraciones y lo dispuesto en los artículos $1,14,15,24,30,50,67$. 69, y 296 N³ del Código Penal; 53, 54, 295, 296, 297, 340, 341, 342, 343 y 346 del Código Procesal Penal,

\section{SE RESUELVE:}

I.- Que se condena a CRISTIAN ANDRES SENZANO GODOY, ya individualizado, a la pena de TRESCIENTOS UN DÍAS DE PRESIDIO MENOR EN SU GRADO MÍNIMO, a la pena accesoria de suspensión de cargo u oficio público durante el tiempo de la condena y al pago de las costas de la causa, como autor del delito de amenaza no condicional, hecho perpetrado en Coquimbo, el día 19 de diciembre de 2000 .

II.- Que, no se concederá beneficios de la Ley 18.216 al imputado, por no existir a su favor los requisitos legales para ello. En consecuencia, el sentenciado deberá cumplir real y efectivamente la pena corporal impuesta, sirviéndole de abono los 98 días que ha permanecido ininterrumpidamente privado de libertad en esta causa desde el 19 de diciembre de 2000 hasta el 26 de marzo del año 2001, fecha de esta sentencia.- 
III.- Que atendido el mérito de los antecedentes y constando del juicio que el acusado cometió el delito de esta causa mientras cumplía el beneficio de la remisión condicional de la pena, concedido en los autos rol 24.076-3, del Segundo Juzgado de Letras de Coquimbo, por robo en lugar no habitado, de acuerdo a lo dispuesto en el artículo 26 de la ley 18.216, dicho beneficio debe entenderse revocado por el sólo ministerio de la ley, debiendo en consecuencia cumplir efectivamente la pena allí impuesta, de quinientos cuarenta y un días de presidio menor en su grado medio, por lo que, a continuación de la sanción que se le impone en el presente juicio, deberá cumplir aquella, sirviéndole de abono el tiempo que para tales efectos se le consideró en la sentencia referida.

IV.- Cumplidas las penas privativas de libertad señaladas, el sentenciado deberá cumplir, además, con el beneficio de la reclusión nocturna que le fuera concedido en el proceso criminal rol $\mathrm{N}^{\circ} 452$ del Tercer Juzgado de Letras de Coquimbo como autor del delito de hurto en perjuicio de Juan Segundo Ugarte Miranda, por hecho ocurrido en la ciudad de Coquimbo el 10 de abril de 1999, en horas de la madrugada, con los abonos que en ella se indican, y que no ha cumplido.

V.- Una vez ejecutoriado este fallo, dése cumplimiento al artículo 468 del Código Procesal Penal, oficiándose a la Contraloría General de la República, al Servicio de Registro Civil y a Gendarmería de Chile; a este último servicio, se deberá adjuntar, además, copia de las sentencias definitivas correspondientes a la del Segundo Juzgado del Crimen de Coquimbo, por el delito de robo en lugar no habitado, causa rol $N^{\circ} 24.076-99$, y del Tercer Juzgado de Letras de Coquimbo, por los delitos de hurto y hurto falta, causa rol $\mathrm{N}^{\circ} 452-99$.

Lo anterior se resuelve con el voto en contra del Juez Enrique Durán Branchi, quien estuvo por ABSOLVER al imputado de la acusación formulada en su contra, aún por el ilícito de amenaza no condicional, ello, en razón al siguiente razonamiento:

a) Que, en la especie no se ha acreditado la apropiación de cosa mueble ajena con ánimo de lucro ni la intimidación en perjuicio de los ofendidos; a este respecto la intimidación en el robo, puede consistir en amenaza, la cual es específica para éste ilícito, consistente en hacer que se entreguen o manifiesten las cosas, o impedir la resistencia u oposición a que se quiten;

b) Atendido lo anterior, no se puede recalificar como amenaza no condicional un hecho que se pretende como de robo con intimidación sin afectar el principio de congruencia, toda vez que cubren situaciones de amenazas diferentes y excluyentes;

c) Tal es la independencia entre ambos ilícitos en comento, que la Ley, además, les ha entregado acciones distintas para que el Estado pueda hacer efectiva su pretensión punitiva. En efecto, el robo con intimidación es delito de acción penal 
pública, y la amenaza no condicional corresponde a los ilícitos penales que la ley procesal llama de acción penal pública previa instancia particular, es decir, de aquellos que requieren para ser promovidos, a lo menos denuncia del ofendido respecto de dicho delito específico, donde se exprese por la víctima que se han vulnerado su seguridad, bien jurídico protegido por ésta;

d) Por otra parte, y sin perjuicio de lo antes expuesto, este voto de minoría estima que a este respecto tampoco se dan los supuestos del inciso $4^{\circ}$ del artículo 54 del Código Procesal Penal toda vez que no se ha aportado en el juicio elemento probatorio alguno que permita concluir que las víctimas se encontraban en la imposibilidad de a lo menos denunciar la amenaza.

Devuélvase a los ofendidos los dos envases de bebidas y el frasco de caramelos presentados al juicio.

Decomísese el machete acompañado en el juicio, y una vez ejecutoriado el fallo, procédase a su destrucción por el señor administrador de este Tribunal, dejándose registro de la ejecución de la diligencia en la carpeta de antecedentes de este juicio.

Redactada por el Juez Sr. Enrique Durán Branchi conjuntamente con su voto disidente.

Rol N¹-2001.-

DICTADA POR LOS JUECES DEL TRIBUNAL DEL JUICIO ORAL EN LO PENAL DE LA CIUDAD DE LA SERENA, SEÑORES JAIME MEZA SAEZ, JORGE FERNÁNDEZ STEVENSON Y ENRIQUE DURÁN BRANCHI. AUTORIZA DOÑA CLAUDIA MOLINA CONTADOR, JEFA UNIDAD ADMINISTRACIÓN DE CAUSAS. 